\title{
Letter
}

Int Neurourol J 2012;16:209-210

http://dx.doi.org/10.5213/inj.2012.16.4.209

pISSN 2093-4777 • eISSN 2093-6931

\section{Bladder Failure?}

\author{
Khae Hawn Kim, Young Ho Kim ${ }^{1}$ \\ Department of Urology, Gachon University Gil Medical Center, Gachon University, Incheon; \\ ${ }^{1}$ Department of Urology, Soonchunhyang University Bucheon Hospital, Soonchunhyang University College of Medicine, Bucheon, Korea
}

In the early 1980s, many urologists and researchers predicted that decompensation of the bladder and the end-stage bladder condition would remain permanent problems throughout all urologic fields or that correction of decompensated bladder would be an innovative field in a faraway future. Actually, the idea of decompensation of the bladder and end-stage bladder was just a hypothesis, abstract theory, or speculation until the advent of the stem cell era [1]. Only decades later, however, since 1992, "the age of regenerative medicine" brought about by the stem cell revolution has become a familiar term even to those with no relation to medical science. In recent years, researchers have developed ways to reprogram ordinary adult somatic cells taken from skin or blood, for example, to create stem cells that can be differentiated into any cell type [2]. These induced pluripotent stem cells offer a supply of multiple types of human cells, such as detrusor muscle cells, bladder cells, and neurons, that can be used for a broad range of laboratory tests in the early stage of drug development. This revolution has begun to transform the approach to failed cells or organs at every level, from translational research at the forefront of biomedical research through our integrated application of this research in clinical practice, even bio-re-engineering. Through advances in stem cell isolation; optimization of culture conditions using proper media, cytokines, and small molecules; and sophisticated cellular and molecular analyses, pluripotent cells can be increased proportionally for use in a clinical setting. The properly functioning urinary bladder is composed of a compliant muscular wall, effective neuromuscular connections, and a highly specialized urothelial layer. Obstruction of the outlet induces deformity of the detrusor muscle and eventually leads to impairment of the proper storage and evacuation of urine. Diverse congenital and acquired medical conditions can cause a progressive loss of bladder function, with eventual progression to failure. When there is mild to moderate bladder impairment, and consecutive conservative methods fail to protect the upper urinary tracts, surgical decompressive intervention or reconstruction of the bladder is usually considered. However, the complications of these surgical interventions, such as the risk of using autologous tissues and the limitations of further or definitive treatments, are well characterized [3]. Regenerative medicine with tissue or cellular engineering has therefore emerged as a surrogate for generating bladder tissue for the treatment of tissue failure. The bladder can lose its ability to store and evacuate effectively as the result of various medical conditions, including idiopathic, inflammatory, neurogenic, toxic, chemical, and overdistention conditions. The end-stage bladder can be characterized as an organ with a fibrous structure, low capacity, poor compliance, and no effective contractility [4]. Bladder dysfunction is a commonly used term. However, bladder dysfunction does not express the end-stage bladder condition. The term dysfunction is difficult to divide into the early and end stages of bladder state. Bladder failure may therefore be better understood by patients who do not use their bladder. This year, the International Neurourology Journal has covered global neurourological trends through special review issues. In this 16th anniversary publication, our featured interest is the term bladder failure from the point of view of end-stage organ failure. Many researchers were unsure about introducing this term. They questioned, "Were we trying to produce a serious work of urology?" However, we believe that the term bladder failure expresses our understanding
Corresponding author: Young Ho Kim

Department of Urology, Soonchunhyang University Bucheon Hospital,

Soonchunhyang University College of Medicine, 170 Jomaru-ro, Wonmi-gu,

Bucheon 420-767, Korea

Tel: +82-32-621-6561 / Fax: +82-32-460-8340

E-mail: yhkuro@schmc.ac.kr

Submitted: December 14, 2012 / Accepted after revision: December 20, 2012
This is an Open Access article distributed under the terms of the Creative Commons Attribution Non-Commercial License (http://creativecommons.org/licenses/by-nc/3.0/) which permits unrestricted non-commercial use, distribution, and reproduction in any medium, provided the original work is properly cited.

Copyright (c) 2012 Korean Continence Society 


\section{INJ kim, etal. Bladder falulue?}

of bladder pathophysiology in this era of regenerative medicine. The field of regenerative medicine has introduced new topics for voiding dysfunction, including decompensated bladder and overactive bladder. We can discover new prospects for functional bladder regeneration from the concept of "failure." We also hope to provide fresh insights into the diagnosis and therapeutic intervention of bladder dysfunction.

\section{REFERENCES}

1. Dayanc M, Kibar Y, Ural AU, Onguru O, Yildiz O, Irkilata HC, et al. The histopathologic, pharmacologic and urodynamic results of mesenchymal stem cell's injection into the decompensated rabbit's bladder. Stem Cell Rev 2012;8:1245-53.

2. Stanasel I, Mirzazadeh M, Smith JJ 3rd. Bladder tissue engineering. Urol Clin North Am 2010;37:593-9.

3. Yagi H, Soto-Gutierrez A, Kitagawa Y. Whole-organ re-engineering: a regenerative medicine approach in digestive surgery for organ replacement. Surg Today 2012 Nov 27 [Epub]. http://dx.doi. org/10.1007/s00595-012-0396-1.

4. Blatt AH, Brammah S, Tse V, Chan L. Transurethral prostate resection in patients with hypocontractile detrusor: What is the predictive value of ultrastructural detrusor changes? J Urol 2012;188:2294-9. 